\title{
EquiLIBRIUM
}

Quarterly Journal of Economics and Economic Policy

2016 VOLUME 11 ISSUE 4, December

p-ISSN 1689-765X, e-ISSN 2353-3293

www.economic-policy.pl

Acedański, J., \& Włodarczyk, J. (2016). Dispersion of Inflation Expectations in the European Union During the Global Financial Crisis. Equilibrium. Quarterly Journal of Economics and Economic Policy, 11(4), 737-749. DOI: http://dx.doi.org/10.12775/ EQUIL.2016.033

Jan Acedański, Julia Włodarczyk*

University of Economics in Katowice, Poland

\section{Dispersion of Inflation Expectations in the European Union During the Global Financial Crisis}

JEL Classification: $C 33 ; C 42 ; D 84 ; E 31$

Keywords: inflation expectations; survey data; global financial crisis; European Union

\begin{abstract}
Inflation expectations, both their median and dispersion, are of great importance to the effectiveness of monetary policy. The goal of this paper is to examine the impact of the global financial crisis on dispersion of inflation expectations in the European Union. Using European Commission's survey data, we find that in the early phase of the crisis the dispersion dropped rapidly but then, after Lehman Brothers' collapse, the trend reversed and these fluctuations cannot be explained by movements of inflation rates and other commonly used factors. We also observe that, in the new European Union member states, the initial drop of the dispersion was weaker whereas the subsequent rise was stronger as compared to the old member states.
\end{abstract}

(C) Copyright Institute of Economic Research

Date of submission: March 27, 2015; date of acceptance: June 12, 2016

*Contact: jan.acedanski@ue.katowice.pl, julia.wlodarczyk@ue.katowice.pl, University of Economics in Katowice, 1 Maja 50, 40-287 Katowice, Poland 


\section{Introduction}

The starting point of this paper is that inflation expectations underlie many consumption and investment decisions, price and wage setting, and thus determine inflation itself. Therefore, low, stable and well-anchored inflation expectations play a decisive role not only for maintaining the price stability over longer periods of time, but also for the effectiveness of monetary policy in case of such major shocks as the global financial crisis. Nevertheless, uncertainty brought about by the global financial crisis may have significantly modified the way economic agents formulate their inflation expectations. For instance, greater dispersion of inflation expectations might negatively affect the monetary policy environment and welfare in crisis-affected countries.

Dispersion (as well as other manifestations of heterogeneity) of inflation expectations seems to be an inherent feature of economic systems. There is a growing body of literature confirming the need to analyze this phenomenon. According to Mankiw et al. (2003), disagreement about future inflation is an interesting variable both for theoretical and practical considerations, because it may be vital for understanding macroeconomic dynamics. High dispersion of inflation expectations changes allocation of resources and implies significant adjustment costs for a large number of individuals if they realize that the actual inflation rate deviates from their initial expectations (Gerlach et al., 2011). Different opinions about future inflation can invite agents to speculate, which in turn may delay or distort actions undertaken by the central bank. They may alter the term structure of interest rates and thus threaten fiscal discipline. They may also affect the distribution of income and wealth as persistence of forecasting errors implies making suboptimal decisions (Gnan et al., 2011). Besides, the dispersion of inflation expectations can be used as a measure of success of inflation targeting countries, because if the inflation target becomes a focal point anchoring inflation expectations, in the long run the dispersion of inflation expectations is likely to decrease (Capistrán \& Ramos-Francia, 2010). Finally, dispersion of inflation expectations is of great importance for monetary unions, where persistent differences in inflation expectations among countries may create external imbalances, destabilizing trade and affecting the effectiveness of supranational monetary policy. Therefore, low dispersion of inflation expectations in a monetary union (such as the euro area) can be treated as one of indicators of convergence in terms of inflation rates (cf. Gnan et al., 2011). 
There are several papers referring to the dispersion of inflation expectations in the euro area after the onset of the global financial crisis. For example, Badarinza \& Buchmann (2009) observed that in the euro area the disagreement about inflation expectations started to rise in the second half of 2007 and rose further with the ongoing crisis. Galati et al. (2011) reported that in the euro area the cross-sectional dispersion of long-run inflation expectations increased in the beginning of 2009. Gerlach et al. (2011) found that the dispersion of professionals' forecasts of five-year inflation in the euro area reached its maximum in the beginning of 2009. Then it started to decline, but it did not return to its pre-crisis level. Gnan et al. (2011) noticed that the dispersion of inflation expectations calculated for the euro area as a whole dropped sharply in 2007 and did not change significantly until the third quarter of 2008. Afterwards, disagreement increased again surpassing the level observed before the introduction of the euro.

However, none of those papers formally examines the impact of the crisis on the dispersion of inflation expectations controlling for factors that influence the expectations like the level of inflation and its variability. Here, we fill this gap and test empirically the hypothesis that uncertainty brought about by the global financial crisis increased the dispersion of inflation expectations in the European Union countries. Contrary to the previous papers, we focus not only on the euro area, but we also include the other members of the European Union. Therefore, we can highlight the important differences between the old and new European Union member states.

The remainder of the paper is structured as follows. In the subsequent sections, we present the data and the measures of ordinal variation that we use in our empirical analysis, and the methodology that we employ. Then, we estimate the impact of the global financial crisis on the dispersion of inflation expectations in the European Union and examine whether all countries observed similar developments. For comparative purposes, we also conduct analysis of perceived inflation. We conclude in the final section.

\section{Data on Expected, Perceived and Actual Inflation}

Our choice of measures of dispersion of inflation expectations (discussed in the next section) is dictated by the character of available data. We use qualitative data on expected and perceived inflation taken from the European Commission's Business and Consumer Survey (European Commission, 
2015). The survey is conducted monthly in the European Union member countries as well as the candidate states. Each month about 300-2000 complete questionnaires are gathered in each country. We are interested in two questions for which respondents can give answers according to a fiveoption ordinal scale, i.e.:

Question 5: How do you think that consumer prices have developed over the past 12 months? They have: (a) risen a lot, (b) risen moderately, (c) risen slightly, (d) stayed about the same, (e) fallen, (f) don't know.

Question 6: By comparison with the past 12 months, how do you expect that consumer prices will develop in the next 12 months? They will: (a) increase more rapidly, (b) increase at the same rate, (c) increase at a slower rate, (d) stay about the same, (e) fall, $(f)$ don't know.

Our sample covers the period 2003-2014. We decided to start our analysis a year after the introduction of the euro because of significant disturbances associated with the formation of inflation expectations in the newly established euro area. We consider the current members of the European Union, but because of data unavailability we have to exclude Luxembourg, Denmark, Ireland and Croatia from the sample. Besides, we do not analyze any aggregate measures of inflation expectations, because they seem to mask the heterogeneity observed across countries (cf. Gnan et al., 2011).

Furthermore, as the actual inflation rate is an explanatory variable in our models, we also extract monthly data on the HICP inflation (Eurostat, 2015) for the period 2002-2014 (with the first 12 observations being used to calculate the yearly changes of the inflation).

On the whole, we work on a balanced panel with 24 countries and 144 monthly observations.

\section{Measurement of Dispersion of Inflation Expectations}

Empirical analyses of dispersion of inflation expectations are usually based on such measures as the standard deviation (e.g. Galati et al., 2011; Gerlach et al., 2011) or the interquartile range (e.g. Mankiw et al., 2003; Trehan \& Zorilla, 2012). However, these measures cannot be calculated directly for qualitative data as they require quantification. Therefore, following Badarinza \& Buchmann (2009) and Gnan et al. (2011), we use the index of ordinal variation proposed by Lacy (2006) as the baseline measure of the dispersion of inflation expectations. 
If $f_{1}, f_{2}, \ldots, f_{k}$ denote cumulative category shares, then the Lacy's index is calculated as follows:

$$
I O V_{\text {Lacy }}=\sum_{i=1}^{k-1} f_{i}\left(1-f_{i}\right)
$$

In our case, $k=5$, because when calculating the dispersion measures, we always exclude the last answer $(f)$ don't know, and adjust the remaining frequencies proportionally to keep the sums equal to $100 \%$. For $k=5$, the index coincides with the measure proposed by Berry and Mielke (1992).

The Lacy's index is designed to measure an average difference between categories and has very intuitive properties: it takes values from the range $[0,1]$, where the value 0 is attained only when all respondents give exactly the same answer. On the other extreme, when $w_{1}=w_{5}=0.5$ (with $w_{i}$ denoting the frequency of the answer $i$ ), the value of the index equals 1 .

For the robustness check purposes, we also consider two other measures. The first is an alternative index of variation for ordinal variables introduced by Leik (1966). The index assesses an average deviation from the median category of the five options and is given by the formula:

$$
I O V_{\text {Leik }}=\frac{\sum_{i=1}^{k} w_{i}|i-m|}{0.5(k-1)} \text {, }
$$

where by $m$ we denote the index of the median answer. It holds similar properties as compared to the Lacy's index.

As for the second measure, we follow the standard practice from the literature and assume the normal distribution of inflation expectations. Then, we estimate the relative standard deviation $\sigma / \pi^{e}$ of the distribution using the formula developed by Berk (1999):

$$
\frac{\sigma}{\pi^{e}}=\frac{2}{z_{1}+z_{2}-z_{3}-z_{4}},
$$

where:

$$
\begin{aligned}
& z_{1}=\Phi^{-1}\left(1-w_{1}\right), \\
& z_{2}=\Phi^{-1}\left(1-w_{1}-w_{2}\right), \\
& z_{3}=\Phi^{-1}\left(1-w_{1}-w_{2}-w_{3}\right),
\end{aligned}
$$


$z_{4}=\Phi^{-1}\left(w_{5}\right)$

$\sigma-$ the standard deviation,

$\pi^{e}$ - the expected inflation rate,

$\Phi^{-1}(\cdot)$ - the inverse of the normal cumulative distribution. In case of $w_{5}=0$, we set $\Phi^{-1}\left(w_{5}\right)=-3$.

All these three dispersion measures are conditional on the perceived inflation. Basically, this comes from the conditional nature of question 6 , in which respondents are asked about their expectations relative to the perceived price change in the previous 12 months (question 5). (In fact, the answers $(d)$ and $(e)$ to question 6 are stated unconditionally, but, nonetheless, they are rarely chosen by respondents.) Throughout the paper, we do not try to use unconditional dispersion measures, because it would inevitably involve estimating cross-section correlations between expected and perceived inflation which seems to be a demanding task without the survey microdata.

\section{Research Methodology}

To assess the impact of the crisis on the dispersion of the inflation expectations, we estimate the following fixed-effects panel model:

$$
y_{i t}=\alpha_{0 i}+\alpha_{1} \pi_{i t-1}+\alpha_{2}\left(\Delta \pi_{i t-1}\right)^{2}+\alpha_{3} d_{c e, t}+\alpha_{4} d_{c m, t}+\alpha_{5} d_{c l, t}+\alpha_{6} d_{\text {euro }, i t},
$$

where:

$y$ - the dispersion measure,

$\pi$ - the annual inflation rate,

$\Delta \pi_{t}=\pi_{t}-\pi_{t-12}$ - the annual change of the inflation rate,

$d_{c e}, d_{c m}, d_{c l}$ - dummy variables representing phases of the financial crisis, and

$d_{\text {euro }}$ is a dummy variable for the euro adoption period.

We set the common dating of the crisis period for all countries, since we are unable to find any comparable criterion for setting the crisis time frames in all countries separately. As already suggested by equation (4), for the purpose of our study, we distinguish three phases of the crisis. The early phase $\left(d_{c e}\right)$, which lasts from July 2007 to August 2008, is associated with a swift rise of inflation rates caused by the oil price rally. At the beginning 
of this period, the first worldwide shortages of liquidity occurred and stock market indices begun to fall. The middle phase $\left(d_{c m}\right)$ starts in September 2008, when Lehman Brothers collapsed, and lasts 10 months, until June 2009. This phase is characterized by a severe recession and rapidly decreasing inflation rates. Finally, the late (recovery) phase $\left(d_{c l}\right)$ ends in June 2010, when GDP growth rates approximately returned to their pre-crisis levels and inflation started to accelerate again. That month, the European Central Bank also ended its first covered bond purchase programme, intended to support a specific financial market segment that had been particularly affected by the financial crisis.

Of course, the proposed phasing is somewhat arbitrary. However, establishing the exact time frames of the global financial crisis is a difficult task as far as expectations are concerned. The difficulties result from the interplay of two features of expectations: forward-lookingness and nonobservability. Observed events as well as rich statistical data offer a sound guidance for the real-economy crisis dating, but are less useful if expectations are investigated. Unfortunately, there is no reasonable alternative to them. Nonetheless, our phasing allows us to highlight the evolution of the expectations' dispersion during the whole crisis.

In our analysis, we also include control variables to capture the correlations between the dispersion measures and the inflation rate as well as the trend in the inflation rate $\left(\Delta \pi_{t}\right)^{2}$. The dummy variable for the euro adoption period is equal one for six months before the euro adoption date, and for another six months after the date and zero otherwise. It accounts for the changes of inflation expectations caused by the euro adoption in some new European Union countries.

\section{Results}

In Table 1 we present the main results of our analysis. The table contains the parameter estimates of the model given by equation (4) for the Lacy's measure of the dispersion of inflation expectations. We report the results for the panel of all studied countries, denoted by full sample, as well as the separate estimates for the panels of the old and the new EU members. 
Table 1. Estimates of panel models for the dispersion of inflation expectations

\begin{tabular}{ccccccccc}
\hline Var. & const. & $\pi_{t-1}$ & $\left(\Delta \pi_{t-1}\right)^{2}$ & $d_{c e}$ & $d_{c m}$ & $d_{c l}$ & $d_{\text {euro }}$ & $R^{2}$ \\
\hline Full & 0.565 & -0.010 & 0.0005 & -0.031 & 0.051 & 0.028 & 0.039 & \multirow{2}{*}{0.62} \\
sample & $(0.004)$ & $(0.001)$ & $(0.0001)$ & $(0.008)$ & $(0.011)$ & $(0.012)$ & $(0.012)$ & \\
\hline Old & 0.609 & -0.014 & 0 & -0.043 & 0.044 & 0.020 & & \multirow{2}{*}{0.59} \\
EU & $(0.005)$ & $(0.003)$ & $(0.0013)$ & $(0.013)$ & $(0.014)$ & $(0.013)$ & & \\
\hline \multirow{2}{*}{ New EU } & 0.529 & -0.010 & 0.0005 & -0.016 & 0.062 & 0.036 & 0.035 & \multirow{2}{*}{0.55} \\
\hline
\end{tabular}

Note: In parentheses, Arellano (1987) robust standard errors are reported. Last column contains the within $R^{2}$, from LSDV regression. "Old EU" panel includes 12 countries: Belgium, Germany, Greece, Spain, France, Italy, Netherlands, Austria, Portugal, Finland, Sweden, United Kingdom. "New EU" panel includes 12 countries: Bulgaria, Czech Republic, Estonia, Cyprus, Latvia, Lithuania, Hungary, Malta, Poland, Romania, Slovenia, Slovakia.

Source: authors' calculations based on European Commission (2015) and Eurostat (2015) data.

As far as the full sample is concerned, in the first phase of the crisis, the dispersion was (on average) lower by 0.031 than the theoretical values predicted by the other explanatory variables. Then, in the middle phase, the dispersion bounced back and, on average, was higher by 0.051 than the theoretical levels. Finally, in the late phase of the crisis, the dispersion also remained high, although the difference was considerably smaller. Nonetheless, all effects are statistically significant at 0.01 significance level. To put the estimates into the right perspective, they can be compared with the unweighted average unconditional standard deviation of the dispersion measure for all panel countries that is equal to 0.065 . From this point of view, the "pure" effects of the crisis do not seem impressive, but one has to keep in mind that they are accompanied by the non-negligible effects of rapid changes in the other explanatory variables, especially the inflation rates.

Generally, a similar pattern is observed in the old European Union member states. Interestingly, the decline in the dispersion in the early phase of the crisis is almost exactly compensated for in the middle phase. However, this is not the case in the new member states, where the initial drop is weak (0.018), but the subsequent rise is significantly stronger. Likewise, in the late phase, the "pure" effect of the crisis remains stronger than in the old members of the European Union. Finally, our results also confirm that the euro adoption by some new European Union countries was associated with a significant increase in the dispersion of inflation expectations. 
To put more light on the differences between the old and the new member states, we run the country level ordinary least squares regressions of the model given by equation (4). The results are reported in Table $2^{1}$.

Table 2. Results of the country level OLS regressions

\begin{tabular}{|c|c|c|c|c|c|c|c|c|}
\hline Cou. & const. & $\pi_{t-1}$ & $\left(\Delta \pi_{t-1}\right)^{2}$ & $d_{c e}$ & $d_{c m}$ & $d_{c l}$ & $d_{\text {euro }}$ & $R^{2}$ \\
\hline $\mathrm{BE}$ & $0.594 * * *$ & $-0.003^{*}$ & -0.0002 & $-0.023^{* *}$ & $0.008^{* * *}$ & $0.024 * * *$ & & 0.20 \\
\hline BG & $509 * * *$ & $-0.011 * * *$ & 0 & $0.037 * *$ & $0.06 * * *$ & $0.043 * * *$ & & 0.62 \\
\hline $\mathrm{CZ}$ & $567 * * *$ & $-0.011^{* *}$ & $0.0012 * * *$ & -0.013 & $0.114 * * *$ & $0.07 * * *$ & & 0.50 \\
\hline $\mathrm{DE}$ & $.556 * * *$ & -0.003 & 0.0004 & $-0.068^{* * *}$ & 0.015 & $0.039 * * *$ & & 0.53 \\
\hline $\mathrm{EE}$ & $0.470 * * *$ & 0 & 0.0001 & -0.037 & $0.132 * * *$ & $0.118 * * *$ & $0.06 * * *$ & 0.38 \\
\hline EL & $0.630 * * *$ & $-0.016 * * *$ & $0.0077 * * *$ & $-0.12 * * *$ & 0.006 & -0.001 & & 0.52 \\
\hline ES & $0.621 * * *$ & -0.026 *** & $-0.0021 * *$ & -0.005 & $-0.037^{*}$ & -0.099 *** & & 0.24 \\
\hline FR & $0.532 * * *$ & $\begin{array}{l}-0.006^{*} \\
\end{array}$ & $-0.0007 *$ & -0.005 & $0.046^{* * *}$ & $0.042^{* * * *}$ & & 0.25 \\
\hline IT & $.574 * * *$ & 0.002 & 0.0034 & $-0.036 * *$ & -0.005 & $-0.062 * *$ & & 0.06 \\
\hline CY & $.545 * * *$ & $0.008^{*}$ & 0.0003 & -0.022 & $0.096^{* * *}$ & 0.107 *** & -0.00 & 0.16 \\
\hline LV & **** & $-0.019 * * *$ & 0.0003 & $0.11 * *$ & $0.223 * * *$ & -0.005 & $0.056^{* * * *}$ & 0.66 \\
\hline LT & $* * *$ & $.021 * * *$ & $0.0022 * * *$ & 0.018 & $0.157 * * *$ & 0.007 & -0.017 & 0.61 \\
\hline $\mathrm{HU}$ & **** & $-0.005 * * *$ & $.0003 *$ & $-0.023 * * *$ & $-0.02 * * *$ & $0.013^{* * *}$ & & 0.23 \\
\hline MT & $97 * * *$ & $-0.044 * * *$ & $-0.0013^{*}$ & $0.112 * *$ & $0.102 * *$ & $-0.112 * * *$ & -0.042 & 0.19 \\
\hline NL & $5 * * *$ & $-0.028 * * *$ & $-0.0064 * * *$ & -0.114 & $0.075 * * *$ & $0.052 * * *$ & & 0.62 \\
\hline AT & $7 * * *$ & -0.018 *** & $0.0012 *$ & $-0.024 * *$ & $0.095 * * *$ & $0.047 * * *$ & & 0.65 \\
\hline PL & $2 * * *$ & & & $-0.017 * *$ & $-0.012 *$ & -0.007 & & 0.36 \\
\hline PT & $* * *$ & & -0.00 & & 0.06 & $0.04 * * *$ & & 0.62 \\
\hline $\mathrm{RO}$ & $0.513^{* * * *}$ & $-0.008 * * *$ & $0.0004 * * *$ & $-0.047 * * *$ & $0.022 *$ & $0.049 * * *$ & & 0.47 \\
\hline SI & $0.611 * * *$ & $-0.008^{*}$ & $0.0007 *$ & $-0.038 * *$ & $0.024^{*}$ & & & 0.20 \\
\hline SK & $0.590 * * *$ & $-0.021 * * *$ & $-0.0005 * *$ & $-0.074 * * *$ & 0.026 & 0.07 *** & $0.044 * * *$ & 0.76 \\
\hline FI & $0.562 * * *$ & $-0.031 * * *$ & 0.0006 & $-0.018^{* *}$ & $0.136^{* * *}$ & $0.079 * * *$ & & 0.66 \\
\hline SE & & & $-0.0021 * *$ & $-0.097 * * *$ & $0.031 * *$ & 0.014 & & 0.30 \\
\hline UK & 0.630 **** & $-0.006^{* * * *}$ & -0.0017 & 0.001 & $0.071 * * *$ & $0.015^{* *}$ & & 0.26 \\
\hline
\end{tabular}

Note: The stars represent significance level: $0.1^{*}, 0.05^{* *}, 0.01^{* * *}$ based on the Newey-West standard errors Shaded are the new EU countries. Abbreviations: BE - Belgium, BG - Bulgaria, CZ - Czech Republic, DE Germany, EE - Estonia, EL - Greece, ES - Spain, FR - France, IT - Italy, CY - Cyprus, LV - Latvia, LT Lithuania, HU - Hungary, MT - Malta, NL - Netherlands, AT - Austria, PL - Poland, PT - Portugal, RO Romania, SI - Slovenia, SK - Slovakia, FI - Finland, SE - Sweden, UK - United Kingdom.

Source: authors' calculations based on European Commission (2015) and Eurostat (2015) data.

${ }^{1}$ In most countries, the dynamics of the dispersion of inflation expectations is primarily driven by the inflation rate. For these countries, acceptable values of $\mathrm{R}^{2}$ coefficients from our regressions can be usually found. The low values of $\mathrm{R}^{2}$ refer to countries where the relationship between the dispersion of inflation expectations and the inflation rate is weak or even statistically insignificant. Although one cannot draw general conclusions from the models with low values of $\mathrm{R}^{2}$, the focus of this paper is mainly on the dynamics of the dispersion of inflation expectations between the countries during the financial crisis depicted by the estimates of the crisis-related dummy variables coefficients. 
Regarding the early phase of the crisis, the drop in the dispersion is observed almost in all old member states (with the only exception of the United Kingdom), whereas the new member states exhibit more heterogeneous outcomes. Particularly, the weak drop in that group reported in Table 1 results mainly from the considerable increase in the dispersion observed in Latvia, Malta and Bulgaria.

On the other hand, there are fewer differences as far as the middle phase is concerned. A significant rise of the dispersion is observed in all countries, except for Spain, Italy, Hungary and Poland. Finally, the heterogeneity of the results becomes stronger again in the last phase. In particular, contrary to the general trend, the dispersion declined in almost all Southern Europe countries.

Finally, we also note that the general conclusions from Table 1 do not apply to Poland. Interestingly, the dispersion in Poland was constantly lower throughout the crisis. This might reflect the relatively weak impact of the crisis on the Polish economy, although one has to bear in mind that a similar drop was observed in Southern Europe, where the crisis was by no means mild.

Table 3. Results for the alternative measures of the inflation expectations dispersion

\begin{tabular}{|c|c|c|c|c|c|c|c|c|}
\hline Var. & const. & $\pi_{t-1}$ & $\left(\Delta \pi_{t-1}\right)^{2}$ & $d_{c e}$ & $d_{c m}$ & $d_{c l}$ & $d_{\text {euro }}$ & $R^{2}$ \\
\hline \multicolumn{9}{|c|}{ Dependent variable: Leik's ordinal variation } \\
\hline $\begin{array}{c}\text { Full } \\
\text { sample }\end{array}$ & $\begin{array}{c}0.417 \\
(0.005)\end{array}$ & $\begin{array}{l}-0.009 \\
(0.002)\end{array}$ & $\begin{array}{c}0.0004 \\
(0.0001)\end{array}$ & $\begin{array}{l}-0.030 \\
(0.009)\end{array}$ & $\begin{array}{c}0.045 \\
(0.011)\end{array}$ & $\begin{array}{c}0.031 \\
(0.013)\end{array}$ & $\begin{array}{c}0.037 \\
(0.011)\end{array}$ & 0.59 \\
\hline $\begin{array}{l}\text { Old } \\
\text { EU }\end{array}$ & & & & $\begin{array}{l}-0.049 \\
(0.012)\end{array}$ & $\begin{array}{c}0.039 \\
(0.015)\end{array}$ & $\begin{array}{c}0.019 \\
(0.015)\end{array}$ & & 0.55 \\
\hline New EU & $\begin{array}{c}0.378 \\
(0.006)\end{array}$ & $\begin{array}{l}-0.009 \\
(0.002)\end{array}$ & $\begin{array}{c}0.0004 \\
(0.0001)\end{array}$ & $\begin{array}{l}-0.002 \\
(0.009)\end{array}$ & $\begin{array}{c}0.056 \\
(0.016)\end{array}$ & $\begin{array}{c}0.042 \\
(0.018)\end{array}$ & $\begin{array}{c}0.030 \\
(0.010)\end{array}$ & 0.51 \\
\hline \multicolumn{9}{|c|}{ Dependent variable: relative standard deviation of the normal distribution } \\
\hline $\begin{array}{c}\text { Full } \\
\text { sample }\end{array}$ & $\begin{array}{c}0.592 \\
(0.003)\end{array}$ & $\begin{array}{l}-0.007 \\
(0.001)\end{array}$ & $\begin{array}{c}0.0004 \\
(0.0001)\end{array}$ & $\begin{array}{l}-0.018 \\
(0.009)\end{array}$ & $\begin{array}{c}0.059 \\
(0.013)\end{array}$ & $\begin{array}{c}0.013 \\
(0.012)\end{array}$ & $\begin{array}{l}-0.005 \\
(0.015) \\
\end{array}$ & 0.58 \\
\hline $\begin{array}{l}\text { Old } \\
\text { EU }\end{array}$ & $\begin{array}{c}0.602 \\
(0.010)\end{array}$ & $\begin{array}{l}-0.011 \\
(0.003)\end{array}$ & $\begin{array}{c}0.0021 \\
(0.0025)\end{array}$ & $\begin{array}{l}-0.024 \\
(0.012)\end{array}$ & $\begin{array}{c}0.057 \\
(0.023)\end{array}$ & $\begin{array}{c}0.013 \\
(0.020)\end{array}$ & & 0.61 \\
\hline New EU & $\begin{array}{c}0.586 \\
(0.005)\end{array}$ & $\begin{array}{l}-0.006 \\
(0.002)\end{array}$ & $\begin{array}{c}0.0004 \\
(0.0001)\end{array}$ & $\begin{array}{l}-0.010 \\
(0.015)\end{array}$ & $\begin{array}{c}0.055 \\
(0.015)\end{array}$ & $\begin{array}{l}-0.001 \\
(0.014)\end{array}$ & $\begin{array}{l}-0.008 \\
(0.017)\end{array}$ & 0.56 \\
\hline
\end{tabular}

In parentheses, Arellano (1987) robust standard errors are reported. Last column contains the within $R^{2}$, from LSDV regression. See also the note below table 1.

Source: authors' calculations based on European Commission (2015) and Eurostat (2015) data. 
For the robustness check purposes, we conduct a similar analysis with the other measures of dispersion. The results are reported in Table 3. As far as the Leik's index is concerned, we do not find any significant differences as compared with the findings already obtained with the Lacy's measure. The two indices differ mainly with respect to their average levels, but the results correlate strongly.

On the other hand, we find more differences for the standard deviation of the normally distributed expectations. In particular, the "pure" effects of the crisis on the dispersion seem to be weaker in the early and the late phases of the crisis. In fact, in the latter case, the effect is statistically insignificant, and simply absent in the new members of the European Union. Moreover, the size of the middle-phase effect is similar for the old and the new member states. Nonetheless, the observed differences are rather mild and do not contradict explicitly the general findings reported above.

Finally, in a similar way, we examine the behavior of the dispersion of perceived inflation measured by question 5 of the survey (see Table 4). As far as the full sample and the old EU panel are concerned, the results are virtually the same as for the inflation expectations. Surprisingly, we do not find the middle-phase impact of the crisis on perceived inflation in the new member states.

Table 4. Estimates of panel models for the dispersion of perceived inflation

\begin{tabular}{ccccccccc}
\hline Var. & const. & $\pi_{t-1}$ & $\left(\Delta \pi_{t-1}\right)^{2}$ & $d_{c e}$ & $d_{c m}$ & $d_{c l}$ & $d_{\text {euro }}$ & $R^{2}$ \\
\hline Full & 0.533 & -0.014 & 0.0009 & -0.051 & 0.038 & 0.029 & 0.016 & \multirow{2}{*}{0.59} \\
sample & $(0.006)$ & $(0.002)$ & $(0.0002)$ & $(0.013)$ & $(0.013)$ & $(0.012)$ & $(0.010)$ & \\
\hline Old & 0.576 & -0.032 & 0.0018 & -0.051 & 0.052 & 0.026 & & \multirow{2}{*}{0.71} \\
EU & $(0.015)$ & $(0.006)$ & $(0.0009)$ & $(0.016)$ & $(0.015)$ & $(0.013)$ & & \multirow{2}{*}{0.013} \\
\multirow{2}{*}{ New EU } & 0.516 & -0.011 & 0.0009 & -0.045 & 0.019 & 0.013 & 0.016 & \multirow{2}{*}{0.46} \\
& $(0.006)$ & $(0.002)$ & $(0.0002)$ & $(0.019)$ & $(0.021)$ & $(0.023)$ & $(0.011)$ & \\
\hline
\end{tabular}

Note: In parentheses, Arellano (1987) robust standard errors are reported. Last column contains the within $R^{2}$, from LSDV regression. See also the note below table 1 .

Source: authors' calculations based on European Commission (2015) and Eurostat (2015) data.

\section{Conclusions}

The results of the study document a clear pattern regarding the behavior of inflation expectations in European Union member countries during the global financial crisis. In the early phase of the crisis, the dispersion signif- 
icantly dropped. However, after Lehman Brothers' collapse, the trend reversed and the dispersion exceeded the typical levels. Therefore, we confirm the findings of Gnan et al. (2011), but contrary to that study we show that the movements cannot be attributed to the behavior of inflation rates and some other commonly used factors. We also estimate the "pure" effects of the crisis on the dispersion during its three phases and show that they are not very impressive compared to the unconditional standard deviation of the dispersion values. Moreover, we highlight that the initial drop of the dispersion in the new European Union member states was weaker, whereas the subsequent rise was stronger than in the old member states.

The country-level analysis reveals some interesting deviations from this pattern. In particular, the dispersion was constantly below the typical levels in Southern Europe countries as well as in Poland and Hungary. The opposite results are obtained for Bulgaria, Lithuania and the United Kingdom.

Naturally, further research could focus on building more comprehensive models including a wider choice of economic and demographic variables. They could analyze not only the overall effect of the global financial crisis on dispersion of inflation expectations, but also more detailed issues such as possible changes in inflation expectations formation (including their unanchoring).

Another possibly important avenue is related to measurement of the dispersion of inflation expectations. In the study, we use the dispersion measures conditioned on perceived inflation that do not take into account the dispersion related to the inflation perception. Employing unconditional measures would definitely put more light on the discussed topic.

\section{References}

Arellano, M. (1987). Computing Robust Standard Errors for Within-groups Estimators. Oxford Bulletin of Economics and Statistics, 49(4). DOI: http://dx.doi. org/10.1111/j.1468-0084.1987.mp49004006.x.

Badarinza, C., \& Buchmann, M. (2009). Inflation Perceptions and Expectations in the Euro Area - the Role of News. ECB Working Paper, No. 1088.

Berk, J. M. (1999). Measuring Inflation Expectations: a Survey Data Approach. Applied Economics, 31(11). DOI: http://dx.doi.org/10.1080/000368499323337.

Berry, K. J., \& Mielke, P. W., Jr. (1992). Assessment of Variation in Ordinal Data. Perceptual and Motor Skills, 74(1). DOI: http://dx.doi.org/10.2466/pms. 1992.74.1.63.

Capistrán, C., \& Ramos-Francia, M. (2010). Does Inflation Targeting Affect the Dispersion of Inflation Expectation. Journal of Money, Credit and Banking, 42(1). DOI: http://dx.doi.org/10.1111/j.1538-4616.2009.00280.x. 
European Commision (2015). Retrieved from http://ec.europa.eu/economy_finance /db_indicators/surveys/time_series/index_en.htm (20.02.2015).

Eurostat (2015). Retrieved from http://ec.europa.eu/eurostat (20.02.2015).

Galati, G., Poelhekke, S., \& Zhou, C. (2011). Did the Crisis Affect Inflation Expectations? International Journal of Central Banking, 7(1).

Gerlach, P., Hördahl, P., \& Moessner R. (2011). Inflation Expectations and the Great Recession. BIS Quarterly Review, March.

Gnan, E., Langthaler, J., \& Valderrama, M. T. (2011). Heterogeneity in Euro Area Consumers' Inflation Expectations: Some Stylized Facts and Implications. Monetary Policy and the Economy, 2(11).

Lacy, M. G. (2006). An Explained Variation Measure for Ordinal Models with Comparison to Other Ordinal R2 Measures. Sociological Methods and Research, 34(4). DOI: http://dx.doi.org/10.1177/0049124106286329.

Leik, R. K. (1966). A Measure of Ordinal Consensus. Pacific Sociological Review, 9(2). DOI: http://dx.doi.org/10.2307/1388242.

Mankiw, N. G., Reis, R., \& Wolfers, J. (2003). Disagreement about Inflation Expectations. NBER Macroeconomics Annual, 18. DOI: http://dx.doi.org/10.2139/ ssrn.417602.

Trehan, B., \& Zorilla, O. (2012). The Financial Crisis and Inflation Expectations. FRBSF Economic Letter, 29. 